\title{
AGPAT9 suppresses cell growth, invasion and metastasis by counteracting acidic tumor microenvironment through KLF4/ LASS2/V-ATPase signaling pathway in breast cancer
}

\author{
Shao-hua Fan ${ }^{1, *}$, Yan-yan Wang ${ }^{2,}{ }^{*}$, Zhi-yong Wu ${ }^{3}$, Zi-feng Zhang ${ }^{1}$, Jun Lu ${ }^{1}$, Meng-qiu \\ $\mathbf{L i}^{1}$, Qun Shan ${ }^{1}$, Dong-mei Wu ${ }^{1}$, Chun-hui Sun ${ }^{1}$, Bin Hu ${ }^{1}$, Yuan-lin Zheng ${ }^{1}$ \\ ${ }^{1}$ Key Laboratory for Biotechnology on Medicinal Plants of Jiangsu Province, School of Life Science, Jiangsu Normal University, \\ Xuzhou, Jiangsu, China \\ ${ }^{2}$ Department of Function Examination, The First People's Hospital of Xuzhou, Jiangsu, China \\ ${ }^{3}$ Obstetrics and Gynecology Hospital, Fudan University, Shanghai, China \\ *These authors have contributed equally to this work
}

Correspondence to:

Yuan-lin Zheng, e-mail: ylzheng@jsnu.edu.cn

Keywords: breast cancer, AGPAT9, acidic tumor microenvironment, proliferation, invasion

Received: February 27, $2015 \quad$ Accepted: June 05, $2015 \quad$ Published: June 17, 2015

\section{ABSTRACT}

Human 1-a cylglycerol-3-phosphate 0-a cyltransferase $\underline{9}$ (AGPAT9) is the gene identified from adipose tissue in 2007. We found AGPAT9 expression was significantly higher in poorly invasive MCF7 human breast cancer cells than the highly invasive MDA-MB-231 cells. AGPAT9 significantly inhibited the proliferation of breast cancer cells in vitro and in vivo. Live-cell imaging and transwell assays showed that AGPAT9 could significantly inhibit the migration and invasive capacities of breast cancer cells. The inhibitory effect of AGPAT9 on metastasis was also observed in vivo in lung metastasis model. AGPAT9 inhibited breast cancer cell proliferation, migration and invasion through, at least in part, suppressing the V-ATPase activity. In addition, increased AGPAT9 expression in MCF-7/ADR cells could increase the chemosensitivity to doxorubicin (Dox). Our findings suggest that increasing AGPAT9 expression may be a new approach that can be used for breast cancer treatment.

\section{INTRODUCTION}

Breast cancer is the most frequent malignancy in women and the second-leading cause of cancer-related deaths [1]. Breast cancer progression depends not only on primary tumor growth but also on the ability of tumor cells to metastasize to distant sites.

The vacuolar- $\mathrm{H}^{+}$-ATPase (V-ATPase) is an important $\mathrm{pH}$ regulatory complex in tumor cells and positively correlated to cancer invasion and metastasis, it is required to mediate signaling pathways, such as the $\mathrm{Wnt} / \beta$-catenin pathway $[2,3]$. V-ATPase uses the energy produced by ATP hydrolysis to pump protons into the extracellular environment. The low $\mathrm{pH}$ of tumor extracellular microenvironment may induce the increased activation of degradative enzymes, such as matrix metalloproteinases (MMPs). Moreover, low extracellular $\mathrm{pH}$ may promote the degradation and remolding of extracellular matrix (ECM) through proteolytic enzyme activation, thus contributing to cancer invasion and metastasis $[4,5]$. V-ATPases are overexpressed in many types of metastatic cancers and positively correlated to their invasion and metastasis [5]. In breast cancer cells, the abundance of V-ATPase on the plasma membrane correlates with an invasive phenotype [6]. Furthermore, V-ATPase inhibitors reduce cell migration in cancer cells with high levels of plasma membrane V-ATPase $[7,8]$. There is evidence that the inhibition of V-ATPase function via knockdown of ATP6VOC (ATPase, $\mathrm{H}^{+}$transporting, lysosomal $16 \mathrm{kDa}$, V0 subunit c) expression could effectively suppress cancer metastasis by the decrease of proton extrusion and the down-regulation of protease activity [9].

LASS2 (Homo sapiens longevity assurance homolog $\underline{2}$ of yeast LAG1), which is also called CERS 2 (Ceramide synthase 2), is the gene identified from a human liver cDNA library and binds to ATP6V0C [10]. Our previous studies have shown that LASS2 was involved in chemotherapeutic outcomes and low LASS2 expression may predict chemoresistance [11]. In addition, we also found higher expression of LASS2 in the breast 
cancer patients was associated with fewer lymph node metastases [12].

KLF4 (ruppel-like factor $\underline{4})$, which is also called $E Z F$ (Epithelial zinc finger protein), is a transcription factor that participates in both tumor suppression and oncogenesis [13]. Transient adenoviral expression of KLF4 in the 4T1 orthotopic mammary cancer model significantly attenuated primary tumor growth as well as micrometastases to the lungs and liver [14]. Overexpression of KLF4 in the highly metastatic MDAMB-231 breast tumor cell line was sufficient to restore E-cadherin expression and suppress migration and invasion [15]. Knockdown of KLF4 in MCF7 cells elevated the growth rate of these cells in the presence of estrogen [13].

AGPAT9 (1-acylglycerol-3-phosphate O-acy ltransferase 9), which is also called LPCAT1 (lysophosphatidylcholine acyltransferase 1) [16-18], is a key enzyme for catalyzing the conversion of glycerol3-phosphate to lysophosphatidic acid in the synthesis of triacylglycerol [19]. Until recently, AGPAT9 was cloned from adipose tissue. AGPAT9 is highly expressed in the lung and spleen, followed by leukocyte, omental adipose tissue, and placenta [20]. AGPAT9 has physiological roles in non-inflammatory platelet-activation factor remodeling pathway [21] and in retinal photoreceptor homeostasis [22]. Only recently, some researchers suggested that AGPAT9 maybe correlate with cancer risk [23, 24]. In this study, we found that AGPAT9 expression was markedly different between MCF7 (poorly invasive breast cancer cells) and MDA-MB-231 (highly invasive breast cancer cells). We further elucidated the molecular mechanism of AGPAT9 involved in breast cancer progression by the in-vitro assays and the in-vivo experiments.

A

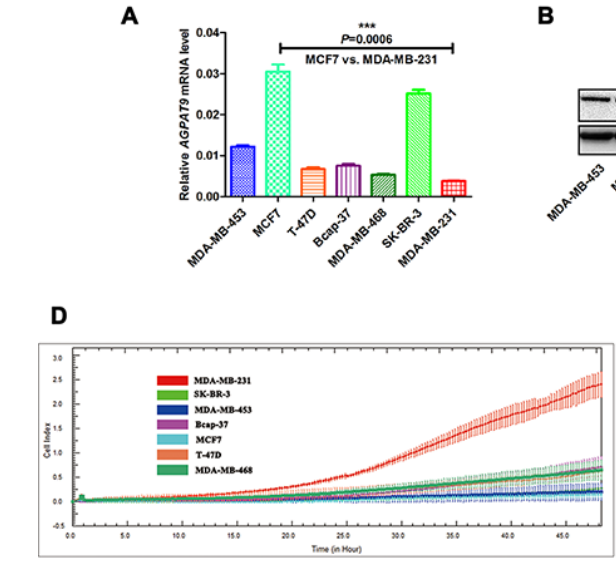

B

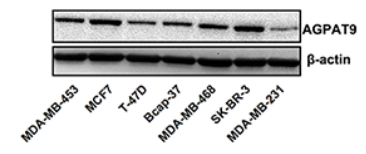

\section{Expression analysis of AGPAT9 in breast cancer cells}

To elucidate the role of AGPAT9 in breast cancer, we first examined the mRNA (Figure 1A) and protein (Figure 1B) expression of AGPAT9 in breast cancer cell lines. AGPAT9 was heterogeneously expressed in various breast cancer cells. MCF7 cells expressed relatively higher levels of AGPAT9 protein than other cells, and MDA-MB-231 cells expressed relatively lower levels of AGPAT9 protein (Figure 1C). To determine if there is a correlation between AGPAT9 protein levels and invasive abilities in breast cancer cell lines, we then examined the invasive ability of these cell lines using the RTCA xCELLigence system. Results showed that MCF7 cells are poorly invasive, and MDA-MB-231 cells are highly invasive (Figure 1D and 1E). These results are consistent with other reports $[25,26]$. Intriguingly, across all cell lines tested, we found a significant inverse correlation between AGPAT9 protein levels and invasive abilities $(P$ $=0.032$; Figure 1F). We chose the relatively AGPAT9highly-expressed cell line MCF7 (poorly invasive breast cancer cells) and the relatively AGPAT9-lowly-expressed cell line MDA-MB-231 (highly invasive breast cancer cells) for functional investigation.

\section{Effect of AGPAT9 on in-vitro proliferation}

We established stable cell lines transduced by a lentivirus carrying the AGPAT9 gene or no insert (vector control), which were designated as Lenti-AGPAT9 and Lenti-vector, respectively, in the breast cancer cell line
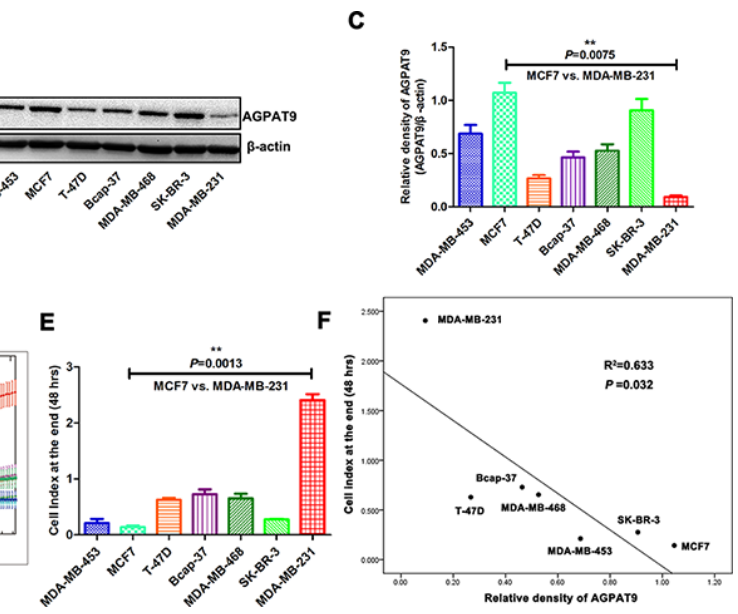

Figure 1: Association between AGPAT9 expression and tumor invasion. The expression levels of $A G P A T 9$ in various breast cancer cell lines were determined by quantitative real-time PCR A. and Western Blotting B. C. Relative density analysis of the AGPAT9 protein bands. The relative density is expressed as the ratio AGPAT9/ $\beta$-actin. D. Real time invasion analysis of seven breast cancer cell lines. The methods were described in MATERIALS \& METHODS. Invasion was monitored for $48 \mathrm{~h}$ in the xCELLigence DP system. The cell index was measured every 15 minutes. The rate of change of cell index as a function of time was calculated as a measure of invasive activity. E. The cell index at the end (48 hrs) is shown as a bar chart. F. Association between AGPAT9 expression and tumor invasion in seven breast cancer cell lines. 
MDA-MB-231 (Figure 2A and 2B). We also established stable cell lines transduced by a lentivirus carrying AGPAT9short hairpin RNA (shRNA) or vector control, which was designated as Lenti-shRNA-AGPAT9 and Lenti-shRNAvector, respectively, in the breast cancer cell line MCF7 (Figure 2C and 2D). In the CCK-8 cell proliferation assay, overexpression of AGPAT9 in MDA-MB-231 cells significantly inhibited cell proliferation with $48 \mathrm{~h}(P=$ 0.0009; Figure 2E), and AGPAT9 knock-down in MCF-7 cells significantly increased cell proliferation with $48 \mathrm{~h}(P=$ 0.0094; Figure 2F). Furthermore, we used the xCELLigence system to analyze cell proliferation in real time (Figure 2G). Results showed overexpression of AGPAT9 in MDAMB-231 cells significantly inhibited cell proliferation with $48 \mathrm{~h}(P<0.0001$; Figure $2 \mathrm{H})$, and AGPAT9 knock-down in MCF-7 cells significantly increased cell proliferation with $48 \mathrm{~h}(P=0.0074$; Figure $2 \mathrm{H})$. These are similar to the results of CCK-8 assay. Moreover, colony formation assay showed that enforced expression of $A G P A T 9$ resulted in a significant decrease in colony numbers in MDA-MB-231 cells compared with the vector controls, and reduced expression of AGPAT9 resulted in a significant increase in colony numbers in MCF7 cells compared to control (Figure 2I).

\section{Effect of AGPAT9 on in-vitro migration and invasion}

Transwell assays without Matrigel demonstrated that overexpression of AGPAT9 could significantly inhibit migration of MDA-MB-231 cells when compared with vector groups $(P=0.0095$; Figure $3 \mathrm{~A}$ and $3 \mathrm{~B})$, and AGPAT9 knockdown in MCF7 cells significantly increased the migration capacity $(P=0.0093$; Figure 3A and 3B). Transwell assays with Matrigel (Catalog Number: 356234, Protein Concentration: $8.95 \mathrm{mg} / \mathrm{ml}$, BD Biosciences, MA) showed that overexpression of AGPAT9 could significantly inhibit the invasive capacity of MDA-MB-231 cells when compared with the control cells $(P=0.0418$; Figure $3 \mathrm{C}$ and $3 \mathrm{D})$, and AGPAT9 knockdown in MCF7 cells significantly increased the invasion capacity $(P=0.0133$; Figure $3 \mathrm{C}$ and $3 \mathrm{D})$. Furthermore, we used the xCELLigence system to analyze cell migration and invasion in real time. Results showed overexpression of AGPAT9 in MDA-MB-231 cells significantly inhibited cell migration with $24 \mathrm{~h}$ $(P=0.0013$; Figure $3 \mathrm{E}$ and $3 \mathrm{~F})$, and AGPAT9 knock-down in MCF-7 cells significantly increased cell migration with $24 \mathrm{~h}(P=0.0278$; Figure $3 \mathrm{E}$ and $3 \mathrm{~F})$. The results also showed overexpression of AGPAT9 in MDA-MB-231 cells significantly inhibited cell invasion with $48 \mathrm{~h}(P=0.0406$; Figure $3 \mathrm{G}$ and $3 \mathrm{H})$, and AGPAT9 knock-down in MCF-7 cells significantly increased cell invasion with $48 \mathrm{~h}(P=$ 0.0272 ; Figure $3 \mathrm{G}$ and $3 \mathrm{H})$. These are similar to the results of Transwell assay. To further confirm this observation, we also determined the migration ability of breast cancer cells in the condition of AGPAT9 overexpression using a confocal scanner system. The results showed that AGPAT9 significantly decreased the migration of MDA-MB-231 cells compared with the vector groups (Figure 3I and 3J; Supplementary Movies S1-S4).

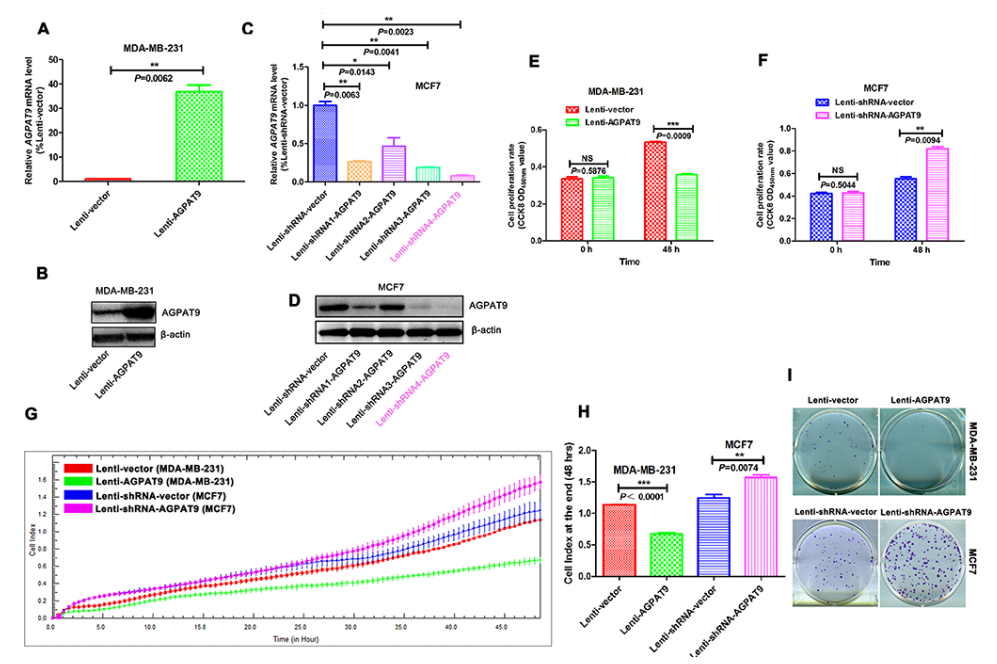

Figure 2: AGPAT9 inhibited breast cancer cell proliferation and clonogenicity in vitro. Real time quantitative PCR A. and western blot B. analyses of AGPAT9 expression in the AGPAT9 over-expression cell lines derived from MDA-MB-231 cells. Real time quantitative PCR C. and western blot D. analyses of AGPAT9 expression in the AGPAT9 knock-down cell lines derived from MCF7 cells. The values shown are expressed as the mean \pm S.E.M. The fragment marked with pink was used in the following functional experiments. In the CCK-8 cell proliferation assay, overexpression of AGPAT9 in MDA-MB-231 cells significantly inhibited cell proliferation E. and AGPAT9 knock-down in MCF-7 cells significantly increased cell proliferation F. Proliferation was monitored for $48 \mathrm{~h}$ in the xCELLigence DP system G. The cell index was measured every 30 minutes. The rate of change of cell index as a function of time was calculated as a measure of proliferation activity. H. The cell index at the end (48 hrs) is shown as a bar chart. I. AGPAT9 over-expression inhibited and AGPAT9-shRNA enhanced cell foci formation ability. ${ }^{*} P<0.05 ; * * P<0.01 ; * * * P<0.001$. 
A

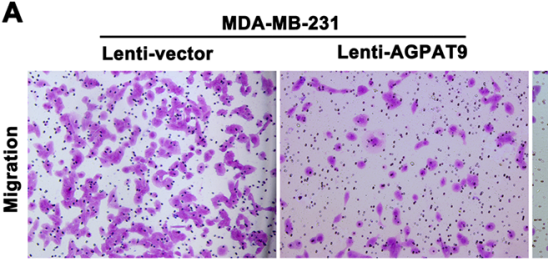

C

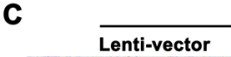

MDA-MB-231

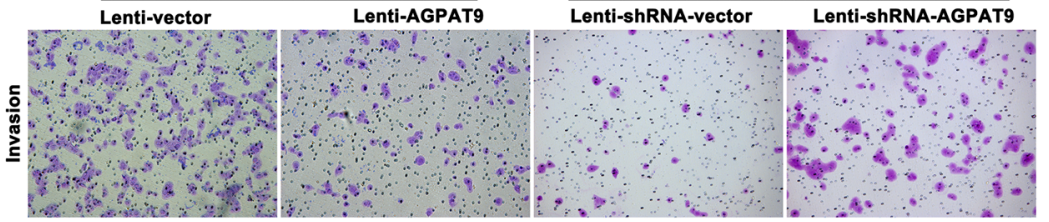

E
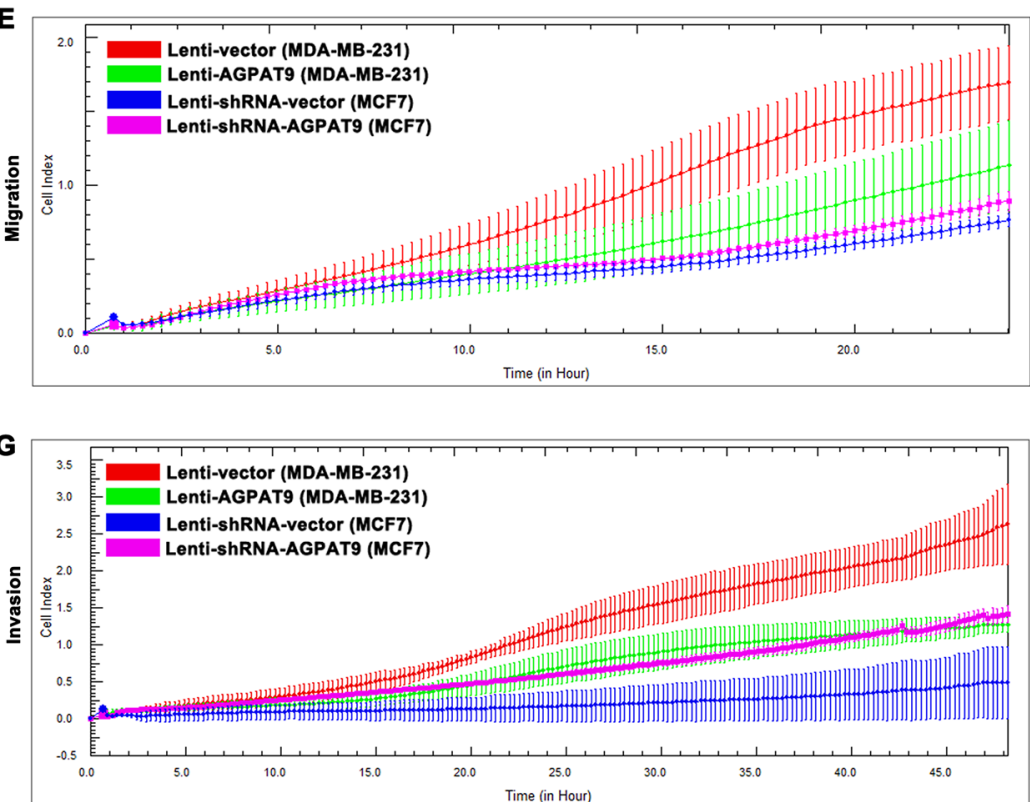

B

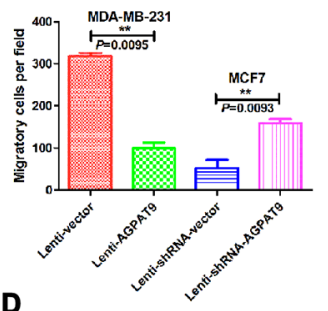

D
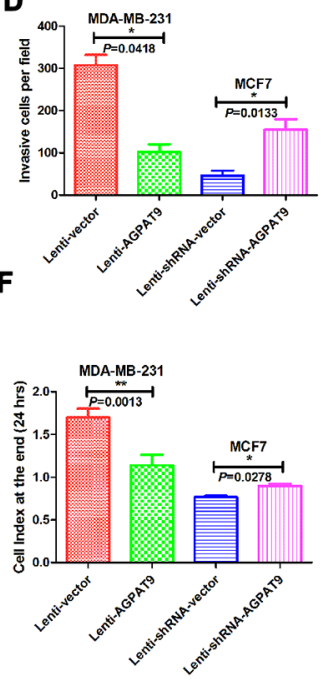

$\mathbf{H}$

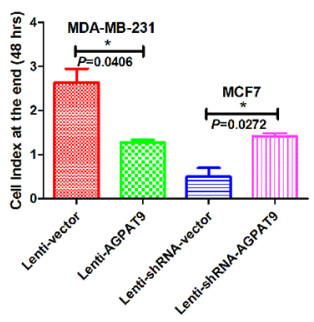

I
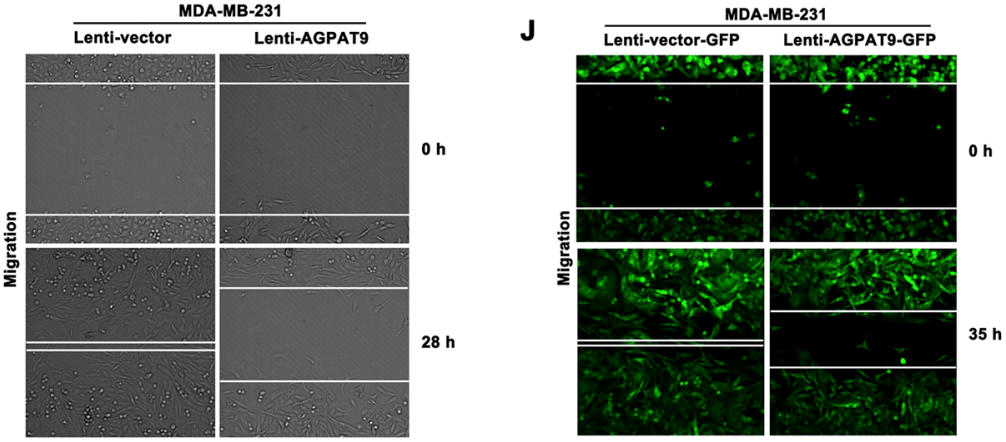

Figure 3: AGPAT9 inhibited breast cancer cell migration and invasion. Transwell assays showed that overexpression of AGPAT9 inhibited the migration A, B. and invasion C, D. rate of MDA-MB-231 cells, and knockdown of AGPAT9 enhanced the migration $(\mathrm{A}, \mathrm{B})$ and invasion $(\mathrm{C}, \mathrm{D})$ rate of MCF7 cells. Migration E. or invasion G. was monitored for $24 \mathrm{~h}$ or $48 \mathrm{~h}$ in the xCELLigence DP system. The cell index was measured every 15 minutes. The rate of change of cell index as a function of time was calculated as a measure of migration or invasion activity. The cell index at the end ( $24 \mathrm{hrs}$ or $48 \mathrm{hrs}$ ) is shown as a bar chart $\mathbf{F}, \mathbf{H}$. The migration of cells into the wound was monitored in multiple wells using a CellVoyager CV1000 confocal scanner system. The images were acquired every 0.5 hour for 28 hours (see Supplementary Movies S1 and S2) or 35 hours (see Supplementary Movies S3 and S4). The images shown represent 0 hour and 28 hours I. The distance between the two edges of the scratch in the Lenti- AGPAT9 well was obviously greater than that of the control. The images shown represent 0 hour and 35 hours $\mathbf{J}$. The distance between the two edges of the scratch in the Lenti-AGPAT9-GFP well was obviously greater than that of the control. ${ }^{*} P<0.05$; $* * P<0.01$. 


\section{AGPAT9 inhibits cell proliferation, migration and invasion by up-regulating $L A S S 2$ expression}

The real-time quantitative RT-PCR assay showed that enforced expression of AGPAT9 resulted in a significant increase in KLF4 $(P=0.0011$; Figure 4A) and LASS2 $(P=0.0090$; Figure 4A) mRNA level in MDAMB-231 cells compared with the vector controls, and reduced expression of AGPAT9 resulted in a significant decrease in KLF4 $(P=0.0069$; Figure 4B) and LASS2 $(P=0.0002$; Figure 4B) mRNA level in MCF7 cells compared to control. Similar results were obtained by western blot analysis (Figure 4C).

Next, we explored whether LASS2 was a transcriptional target of KLF4. Chromatin immunoprecipitation (CHIP) assay showed that KLF4 directly bound to the promoter region of LASS2 in MDA-MB-231 or MCF7 cells (Figure 4D). The results demonstrate that
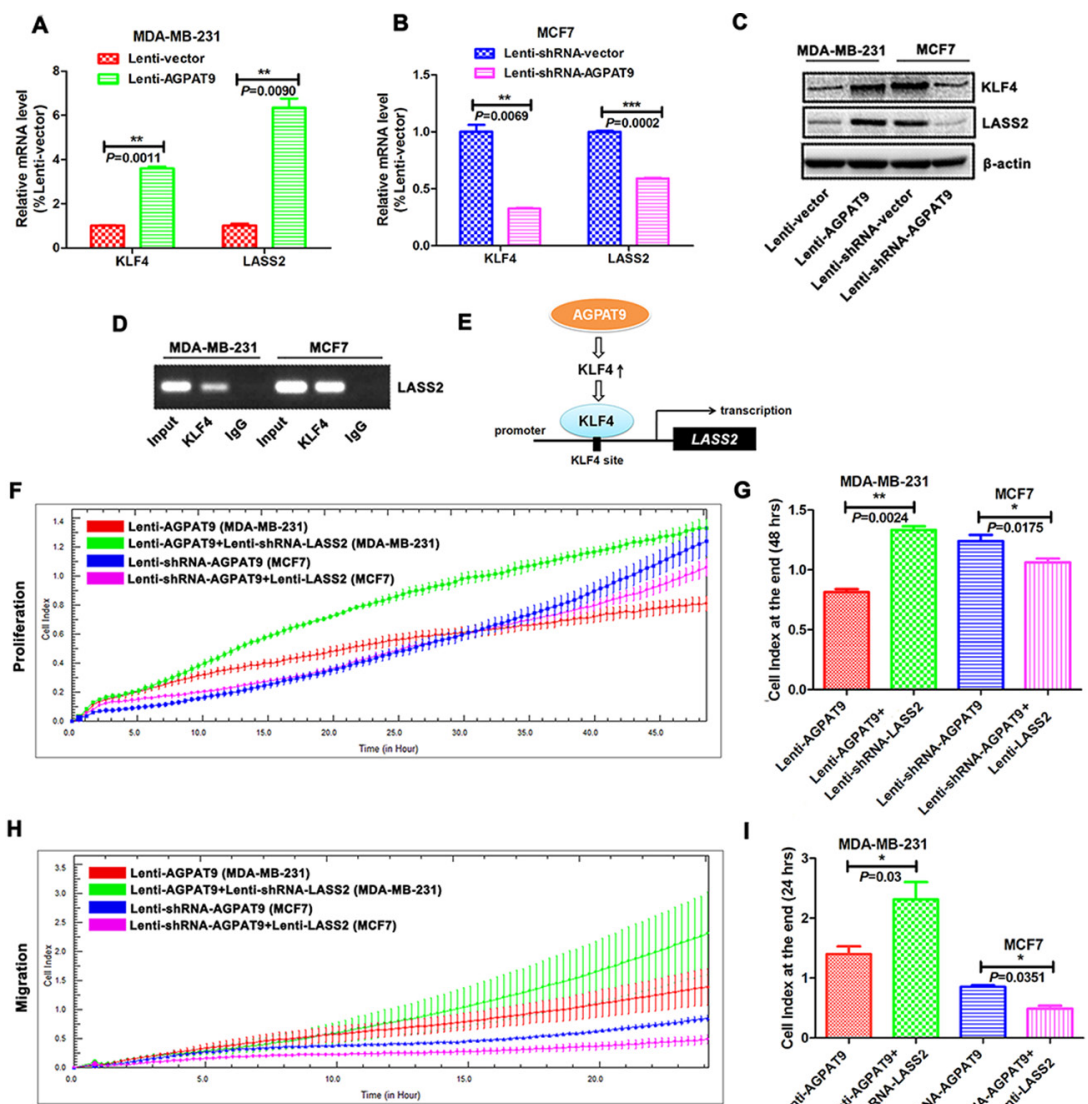

I
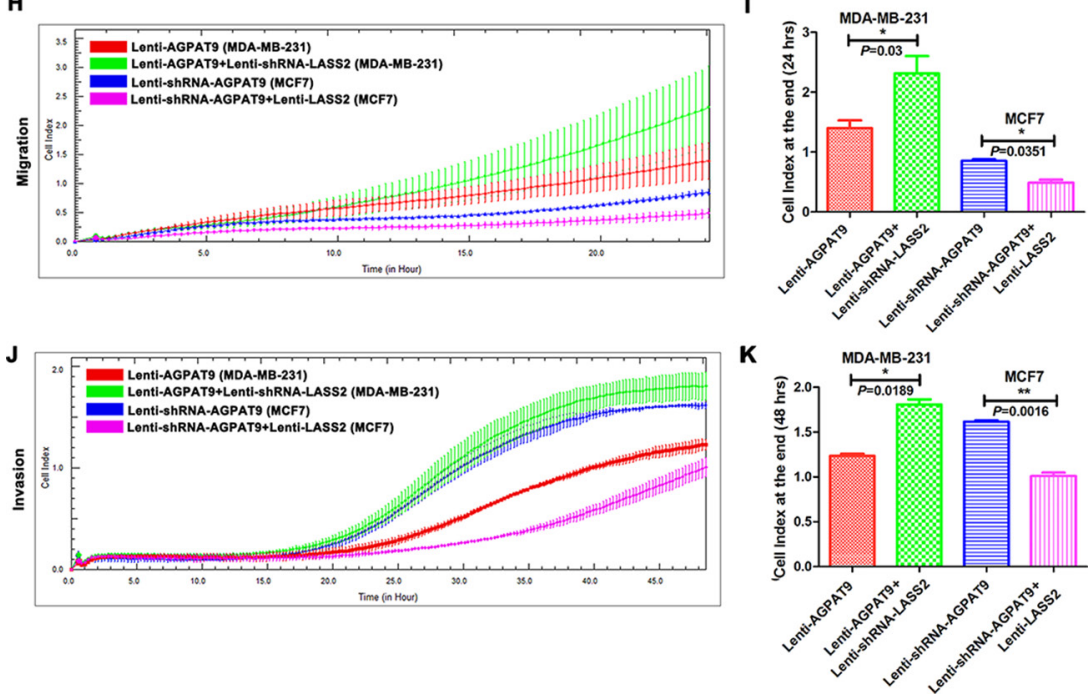

Figure 4: AGPAT9 overexpression resulted in increased expression of $\boldsymbol{L A S S} 2$. The real-time quantitative RT-PCR and western blot assays showed that enforced expression of $A G P A T 9$ resulted in a significant increase in KLF4 and LASS2 mRNA A. and protein C. level in MDA-MB-231 cells, and reduced expression of AGPAT9 resulted in a significant decrease in KLF4 and LASS2 mRNA B. and protein (C) level in MCF7 cells. D. ChIP assay was performed with antibody against KLF4 or control IgG in MDA-MB-231 and MCF7 cells. The immunoprecipitated DNA was analyzed by PCR followed by agarose gel electrophoresis. E. Schematic diagram. RTCA assay showed that reduced expression of LASS2 in Lenti-AGPAT9 (MDA-MB-231) cells could significantly increase cell proliferation F, G. migration H, I. and invasion J, K. compared with the Lenti-AGPAT9 (MDA-MB-231) cells, and enforced expression of LASS2 in LentishRNA-AGPAT9 (MCF7) cells could significantly inhibit cell proliferation (F, G), migration (H, I) and invasion (J, K) compared with the Lenti-shRNA-AGPAT9 (MCF7) cells. ${ }^{*} P<0.05 ; * * P<0.01 ; * * * P<0.001$. 
the expression of LASS2 is transcriptionally activated by KLF4 and LASS2 is a target gene of KLF4 (Figure 4D and $4 \mathrm{E}$ ). Intriguingly, RTCA proliferation assay showed that reduced expression of LASS2 in Lenti-AGPAT9 (MDA-MB-231) cells could significantly increase cell proliferation compared with the Lenti-AGPAT9 (MDAMB-231) cells $(P=0.0024$; Figure $4 \mathrm{~F}$ and $4 \mathrm{G})$, and enforced expression of LASS2 in Lenti-shRNA-AGPAT9 (MCF7) cells could significantly inhibit cell proliferation compared with the Lenti-shRNA-AGPAT9 (MCF7) cells $(P=0.0175$; Figure $4 \mathrm{~F}$ and $4 \mathrm{G})$. Furthermore, RTCA migration assay showed that reduced expression of LASS2 in Lenti-AGPAT9 cells could significantly increase cell migration compared with the Lenti-AGPAT9 cells $(P=0.03$; Figure $4 \mathrm{H}$ and $4 \mathrm{I})$, and enforced expression of LASS2 in Lenti-shRNA-AGPAT9 cells could significantly inhibit cell migration compared with the Lenti-shRNAAGPAT9 cells ( $P=0.0351$; Figure $4 \mathrm{H}$ and $4 \mathrm{I})$. In addition, RTCA invasion assay showed that reduced expression of LASS2 in Lenti-AGPAT9 cells could significantly increase cell invasion compared with the Lenti-AGPAT9 cells $(P=0.0189$; Figure $4 \mathrm{~J}$ and $4 \mathrm{~K})$, and enforced expression of LASS2 in Lenti-shRNA-AGPAT9 cells could significantly inhibit cell invasion compared with the Lenti-shRNA-AGPAT9 cells ( $P=0.0016$; Figure 4J and $4 \mathrm{~K})$. Collectively, these data suggest that AGPAT9 inhibits breast cancer proliferation, migration and invasion through, at least in part, up-regulating the mRNA and protein levels of LASS2.

\section{Effect of AGPAT9 on the V-ATPase activity, $\mathrm{pH}_{\mathrm{e}}$ and $\mathrm{pH}_{\mathrm{i}}$}

In this study, we found that AGPAT9 could significantly increase the mRNA and protein levels of LASS2. In previous study, we reported that LASS2 could inhibit the activity of V-ATPase proton pump through binding to ATP6V0C, the subunit of V-ATPase proton pump $[11,27]$. Therefore, we examined the influence of AGPAT9 on the V-ATPase activity. Overexpression of AGPAT9 in MDA-MB-231 cells significantly reduced the V-ATPase activity $(P=0.0351$; Figure 5A), and $A G P A T 9$ knockdown in MCF7 cells significantly increased the V-ATPase activity $(P=0.0496$; Figure 5A).

$\mathrm{V}$-ATPases are involved in maintaining a relatively neutral intracellular $\mathrm{pH}$ and an acidic extracellular $\mathrm{pH}$, through pumping protons into extracellular environment [11]. In this study, the process of proton extrusion was investigated by detecting the proton concentration in the medium with $\mathrm{pH}$-sensitive BCECF. As shown in Figure 5B, the proton secretion of Lenti-AGPAT9 (MDA-MB-231) was notably reduced at $9 \mathrm{~h}$ compared with that of Lenti-vector (MDA-MB-231) $(P=0.0136$; Figure 5B). Furthermore, the proton secretion of LentishRNA-AGPAT9 (MCF7) was significantly increased compared with that of Lenti-shRNA-vector (MCF7) cells $\left(P=0.0414\right.$; Figure 5C). The $\mathrm{pH}_{\mathrm{i}}$ (intracellular $\left.\mathrm{pH}\right)$ recovery from intracellular acidification induced by $\mathrm{NH}_{4} \mathrm{Cl}$ prepulse is shown in Figure 5D-5E. When exposed to $\mathrm{NH}_{4} \mathrm{Cl}, \mathrm{pH}_{\mathrm{i}}$ increased rapidly and then decreased gradually. After the removal of $\mathrm{NH}_{4} \mathrm{Cl}, \mathrm{pH}_{\mathrm{i}}$ dropped rapidly. In the following procedure, the $\mathrm{pH}_{\mathrm{i}}$ of Lenti-vector cells recovered (Figure 5D), whereas it hardly recovered in Lenti-AGPAT9 cells (Figure 5E). The results indicate that overexpression of AGPAT9 results in inhibition of $\mathrm{pH}_{\mathrm{i}}$ recovery due to AGPAT9 suppressing the function of V-ATPase in Lenti-AGPAT9 cells.

\section{Effect of AGPAT9 on the MMP-2 activity, MMP- 9 activity and Wnt/ß-catenin pathway}

The supernatant of cultured cells was collected and the activities of MMP-2 and MMP-9 were assayed with MMP-2/MMP-9 Activity Assay kit. Intriguingly, overexpression of AGPAT9 in the MDA-MB-231 cells could significantly decrease the active MMP-2 level in the supernatant of cultured cells $(P=0.0111$; Figure 5F). Knockdown of AGPAT9 in the MCF7 cells could significantly increase the active MMP-2 level in the supernatant of cultured cells $(P=0.0097$; Figure 5F). Our results also showed overexpression of AGPAT9 in the MDA-MB-231 cells could significantly decrease the active MMP-9 level in the supernatant of cultured cells $(P=0.0202$; Figure 5G). Knockdown of AGPAT9 in the MCF7 cells could significantly increase the active MMP9 level in the supernatant of cultured cells $(P=0.0027$; Figure 5G). These results showed that AGPAT9 have significant effects on the active MMP-2 and MMP-9 levels in the supernatant.

The Wnt/ $\beta$-catenin pathway is one of the most important signal transduction pathways in breast cancer cell growth. The accumulation of $\beta$-catenin in the cells, especially in the nucleus, is considered as an important indicator of the activation of $\mathrm{Wnt} / \beta$-catenin pathway [28]. Our results showed that reduced expression of AGPAT9 in MCF7 cells could result in an obvious increase in $\beta$-catenin protein level in both nucleus and cytoplasm compared to control (Figure $5 \mathrm{H}$ ). Furthermore, expression of $\mathrm{Wnt} / \beta$ catenin pathway target genes, $c-M y c$, Cyclin D1, Axin-2 and $C D 44$ were significantly increased in the Lenti-shRNAAGPAT9 (MCF7) cells when compared with control cells (Figure 5I). Collectively, these data suggest that AGPAT9 influences breast cancer proliferation through, at least in part, regulating the Wnt/ $\beta$-catenin pathway (Figure $5 \mathrm{~J}$ ).

\section{Effect of AGPAT9 on in vivo proliferation and metastasis}

To determine the in vivo effects of AGPAT9, we performed in vivo proliferation and metastasis study. The average size and weight of xenografts in the Lenti-shRNAAGPAT9 (MCF7) group were dramatically larger and heavier than those of the control group $(P=0.0293$ and $P<0.0001$, respectively). (Figure 6A-6D). Furthermore, 


\section{A}

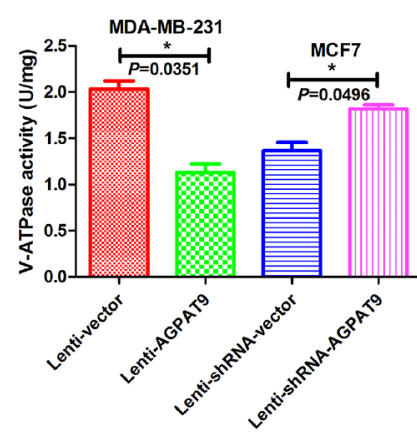

D

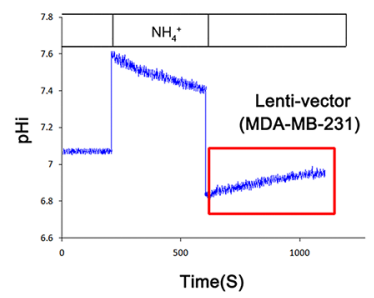

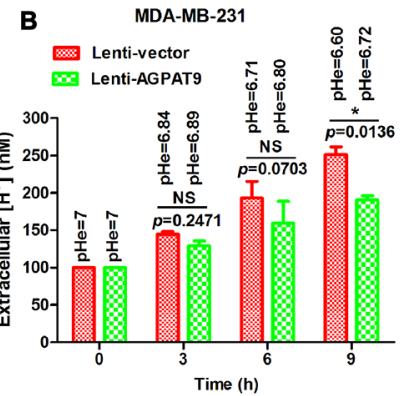

E

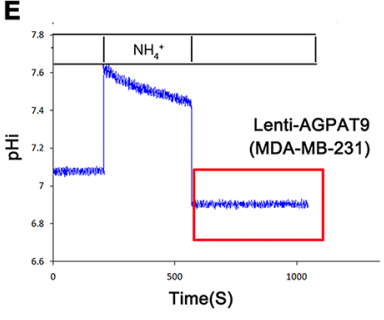

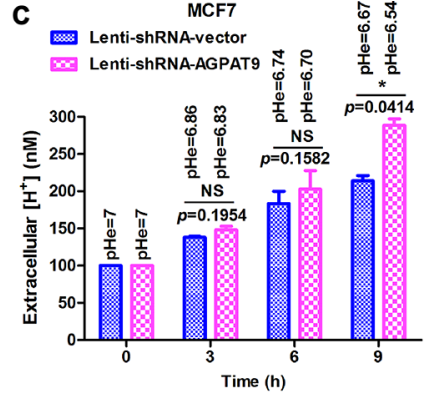

$\mathbf{F}$

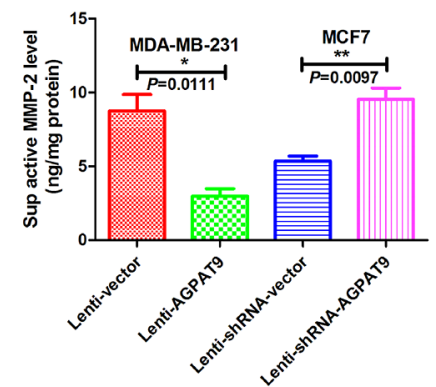

G

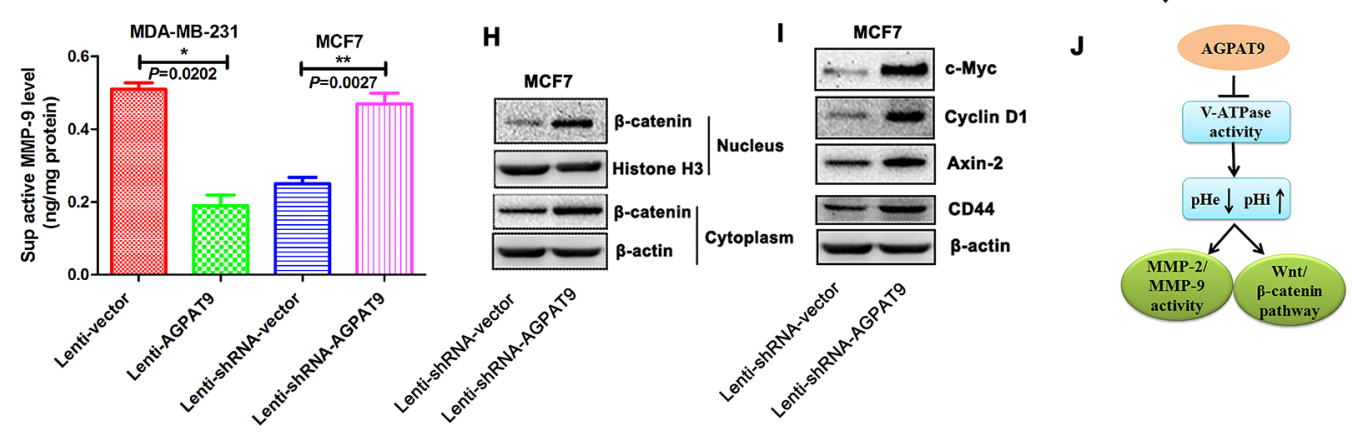

Figure 5: Effect of AGPAT9 on the V-ATPase activity, MMP-2 activity, MMP-9 activity and Wnt/ $\beta$-catenin pathway. A. Activity of V-ATPase in Lenti-AGPAT9 and Lenti-shRNA-AGPAT9 cells. B. Proton secretion was decreased in the Lenti-AGPAT9 cells compared with the Lenti-vector. C. Proton secretion was increased in the Lenti-shRNA-AGPAT9 cells compared with the Lenti-shRNAvector. D, E. $\mathrm{pH}_{\mathrm{i}}$ recovery analysis. The cells were pulsed with $40 \mathrm{mmol} / \mathrm{NH}_{4} \mathrm{Cl}$ and acid loaded by exposure to a $\mathrm{Na}^{+}$and $\mathrm{NH}_{4}{ }^{+}$-free solution. The $\mathrm{pH}_{\mathrm{i}}$ in Lenti-vector cells (D) recovered from the acid load. Lenti- AGPAT9 (E) did not recover to the baseline (indicated in red). The resting $\mathrm{pH}_{\mathrm{i}}$ in Lenti-AGPAT9 cells decreased compared with Lenti-vector cells because of the defect of V-ATPase activity in Lenti-AGPAT9 cells. Active MMP-2 F. and active MMP-9 G. levels in culture supernatants were measured using the enzyme-linked immunosorbent assay (ELISA). Reduced expression of AGPAT9 in MCF7 cells could result in an obvious increase in $\beta$-catenin protein level in both nucleus and cytoplasm compared to control $\mathbf{H}$. The expression of Wnt/ $\beta$-catenin pathway target genes, $c-M y c, C y c l i n D 1, A x i n-2$ and CD44 were significantly increased in the Lenti-shRNA-AGPAT9 (MCF7) cells when compared with control cells I. J. Schematic diagram. $* P<0.05 ; * * P<0.01$.

we injected Lenti-vector (MDA-MB-231) or LentiAGPAT9 (MDA-MB-231) cells into the lateral tail veins of nude mice $(n=10)$ and evaluated the metastatic growth of cells in the lung. After 100 days, the Lenti-AGPAT9 mice displayed a statistically significantly lower number of lung metastases than the control group mice $(P=0.0004$; Figure $6 \mathrm{E}$ and $6 \mathrm{~F}$ ), indicative of extravasation and tumor growth in the lung. When lungs underwent hematoxylin and eosin staining, lung metastases were observed in all ten mice intravenously injected Lenti-vector cells (Figure $6 \mathrm{E}$, up), whereas much less lung metastases were observed in the mice intravenously injected Lenti-AGPAT9 cells (Figure 6E, down).

\section{Effect of AGPAT9 on chemosensitivity}

We found that the AGPAT9 was significantly decreased at mRNA level (-240.368-fold, $P=0.0006$, Supplementary Figure S1A) in the drug-resistant breast cancer cell line MCF7/ ADR than in the drug-sensitive breast cancer cell line MCF7. Next, we established stable cell lines transduced by a lentivirus carrying the AGPAT9 gene or no insert (vector control) in the MCF7/ADR cells. Overexpression of AGPAT9 in MCF7/ ADR cells significantly reduced the $\mathrm{IC}_{50}$ value for Dox $(P$ $=0.0146$; Supplementary Figure S1B). To investigate the influence of AGPAT9 on the subcellular distribution of Dox in the cells, AGPAT9-overexpressing cells and control cells were 


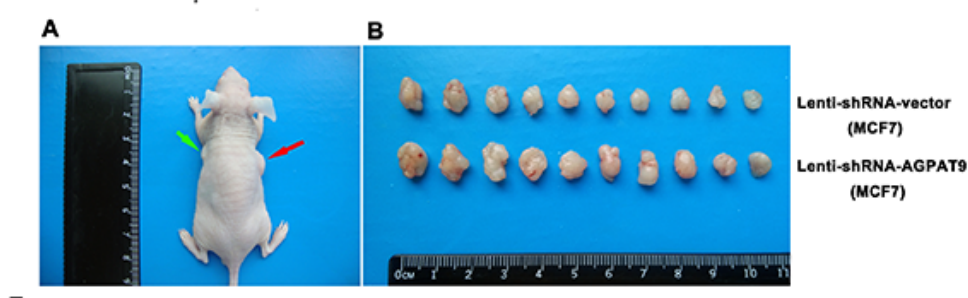

C
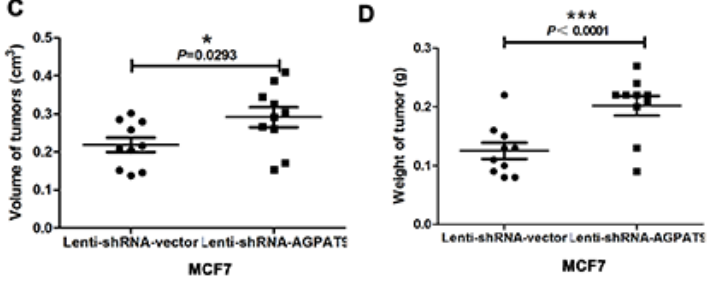

E

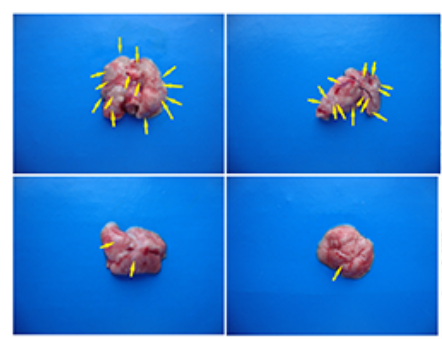

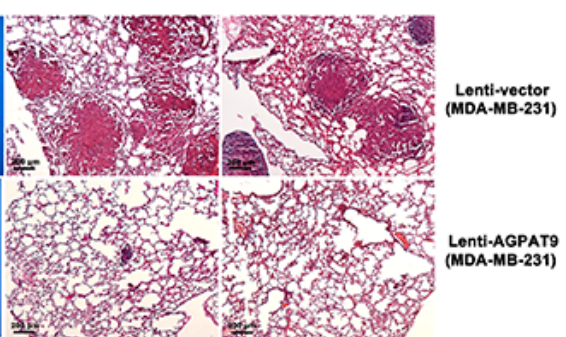

$\mathbf{F}$

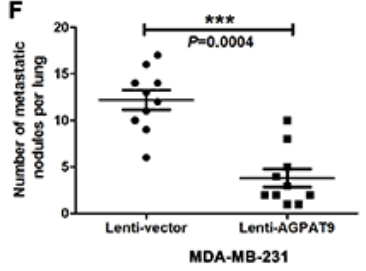

Figure 6: AGPAT9 inhibited tumorigenic and spontaneous lung metastatic capabilities of breast cancer cells. A. 17 $\beta$-Estradiol pellets were subcutaneously implanted into the left shoulder area of mice (green arrow) 3 days before tumor cell injection. The red arrow shows the tumor. B. The photo of tumors isolated from sacrificed nude mice of the indicated groups. C, D. the volume and weight of the tumors. E. Representative H\&E stained sections of the lung tissues isolated from mice that injected with Lenti-Vector or Lenti-AGPAT9 cells through the lateral tail vein, Arrow head points to the tumor focus formed in the lung. F. The numbers of metastases in the lungs were counted. Scale bars: $200 \mu \mathrm{m}(\mathrm{E}) * P<0.05 ; * * * P<0.001$.

treated with Dox (Supplementary Figure S1C). After uptake by MCF7 cells, Dox was localized mostly in the nuclei, which is in line with the sensitivity of these cells to the cytotoxic effect of Dox. In contrast, Dox was localized in discrete granules in the cytosol and barely detectable in the nuclei of control and Lenti-vector (MCF7/ADR) cells. However, in Lenti-AGPAT9 (MCF7/ADR) cells, Dox was localized in the nuclei, as assayed by confocal fluorescence microscopy. These results indicate that enforced expression of AGPAT9 in MCF7/ADR cells results in a clear nuclear targeting of Dox. In addition, we also determined the migration ability of breast cancer cells in the condition of AGPAT9 overexpression using a confocal scanner system. The results showed that AGPAT9 significantly decreased the migration of MCF7/ADR cells compared with the vector groups (Supplementary Figure S2; Supplementary Movies S5 and S6).

\section{DISCUSSION}

Evidences are accumulating that acidic tumor microenvironment is involved in cancer progression [29, 30]. The V-ATPase is the primary regulator of the tumor microenvironment, by means of proton extrusion to the extracellular medium. Several V-ATPase inhibitors have been reported to inhibit cancer cell proliferation, invasion and metastasis $[8,31]$.

In this study, we found that the mRNA level of AGPAT9 in MDA-MB-231 cells (highly invasive breast cancer cells) was significantly lower than in MCF7 cells (poorly invasive breast cancer cells) (-8.06-fold; Figure 1A). Furthermore, we confirmed this differential expression at the protein level (-11.24-fold; Figure 1B and 1C). Intriguingly, across all breast cancer cell lines tested, we found a significant inverse correlation between AGPAT9 protein levels and invasive abilities $(P=0.032$; Figure $1 \mathrm{~F})$. The in-vitro data showed overexpression of AGPAT9 in MDA-MB-231 cells significantly inhibited cell proliferation, migration and invasion (Figures 2 and 3). The in-vitro data also showed AGPAT9 knock-down in MCF7 cells significantly increased cell proliferation, migration and invasion (Figures 2 and 3). Similar results were obtained in in-vivo experiments (Figure 6). Furthermore, overexpression of AGPAT9 in Bcap-37 cells significantly inhibited cell proliferation, migration and invasion, and AGPAT9 knockdown in Bcap-37 cells significantly increased cell proliferation, migration and invasion (Supplementary Figure S3).

KLF4 inhibits breast cancer cell proliferation, migration and invasion $[13,15]$. We found that enforced expression of $A G P A T 9$ resulted in a significant increase in KLF4 mRNA level, and reduced expression of AGPAT9 resulted in a significant decrease in KLF4 mRNA level. Similar results were obtained by western blot analysis. Further study is underway to explore the mechanism that AGPAT9 increases expression of KLF4. Our previous study indicated that LASS2 inhibited cancer cell proliferation, migration and invasion [11, 27]. Furthermore, we found that the expression of LASS2 is transcriptionally activated by KLF4 and LASS2 is a target gene of KLF4. In previous study, we reported that LASS2 could inhibit the V-ATPase activity through binding to ATP6V0C, the c subunit of V-ATPase proton pump [11, 27]. Furthermore, we found that inhibition of V-ATPase activity by knocking down ATP6V0C expression in MDA-MB-231 cells significantly reduced the migration (Supplementary Figure S4; Supplementary Movies S7 and S8). These results suggest that AGPAT9 may inhibit malignant progression of 
breast cancer by inhibiting the V-ATPase activity through increasing the LASS2 expression. To explore this possibility, we examined the influence of AGPAT9 on the V-ATPase activity, $\mathrm{pH}_{\mathrm{e}}$ and $\mathrm{pH}_{\mathrm{i}}$ in the breast cancers. The results showed that overexpression of AGPAT9 could reduce the $\mathrm{V}$-ATPase activity (Figure 5A), increase the $\mathrm{pH}_{\mathrm{e}}$ (Figure 5B) and decrease the $\mathrm{pH}_{\mathrm{i}}$ (Figure 5D and 5E) in MDA-MB-231 cells. Meanwhile, AGPAT9 knockdown in MCF7 cells significantly increased the V-ATPase activity (Figure 5A).

The promoting effect of V-ATPase on cancer invasion mainly relies on its maintain acidic $\mathrm{pH}$ of extracellular microenvironment, which is related to the activation of many proteases involved in the digestion of ECM [9]. The pH-sensitive proteases include cathepsin (cathepsin B, D, etc.) and MMPs (MMP-2, MMP-9, MMP-3, etc.) [9, 32]. Intriguingly, AGPAT9 overexpression in invasive MDA-MB-231 cells is associated with decreased activities of MMP-2 and MMP-9, whereas suppression of AGPAT9 had the opposite effects on MMPs in non-invasive MCF7 cells (Figure 5F and 5G). AGPAT9 inhibits breast cancer invasion through, at least in part, upregulating the activities of MMP-2 and MMP-9 (Figure $5 \mathrm{~F}$ and $5 \mathrm{G})$. Very recently, some researchers found that $\mathrm{V}$-ATPase was required to mediate $\mathrm{Wnt} / \beta$-catenin signaling $[2,33,34]$. Wnt $/ \beta$-catenin signaling is important for cell proliferation. Activation of the $\mathrm{Wnt} / \beta$-catenin signaling stimulates cell growth. V-ATPase generates a proton gradient that is essential for LRP6 phosphorylation and hence $\beta$-catenin activation [2]. AGPAT9 inhibits breast cancer proliferation through, at least in part, regulating the Wnt/ $\beta$-catenin pathway (Figure $5 \mathrm{H}$ and $5 \mathrm{I}$ ).
Doxorubicin (Adriamycin) belongs to the family of anthracyclines. It is membrane permeable in its neutral form and relatively membrane impermeable when protonated [35]. Therefore, the acid $\mathrm{pH}_{\mathrm{e}}$ of cancer cells can make Dox become protonated and hinder it from entering the cells [36]. Chemotherapeutic agents are distributed throughout the cytoplasm and nucleus of drug-sensitive cells. In contrast, in MDR cells, they accumulate only within discrete cytoplasmic organelles, and almost none is detectable in the nucleus, the target of anthracycline drugs $[37,38]$. We found that the overexpression of AGPAT9 increased the susceptibility to Dox cytotoxicity in MCF7/ ADR cells. This effect might be caused by a significant increase in $\mathrm{pH}_{e}$, and more Dox entered the cells and stayed in the nuclei of cell (Supplementary Figure S1C).

In summary, we first delineate the molecular mechanism that AGPAT9 inhibits human breast cancer cells proliferation, invasion and metastasis (Figure 7). Our findings suggest that increasing AGPAT9 expression may be a new approach that can be used for breast cancer treatment and imply that acidic tumor microenvironment may be considered as an important influential factor of antitumor therapeutic efficacy.

\section{MATERIALS AND METHODS}

\section{Cell lines}

Human breast cancer cell lines, T-47D, SK-BR-3, MDA-MB-468, MDA-MB-453, MDA-MB-231 and MCF7, were purchased from the American Type Culture

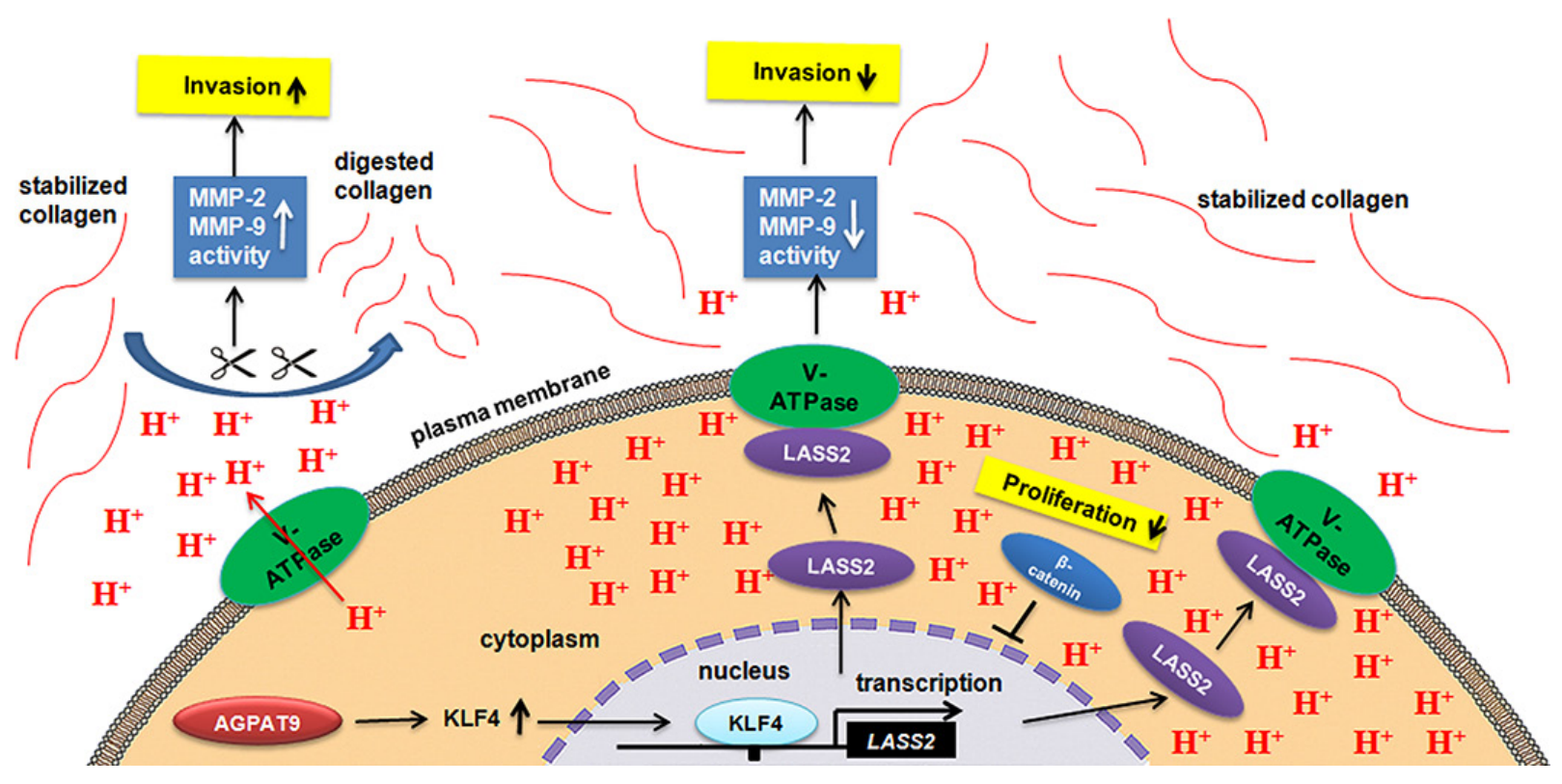

Figure 7: Effect of AGPAT9 on the Wnt/ $\beta$-catenin pathway. A hypothetical cascade pathway of the suppression of tumor cell invasion and proliferation by AGPAT9. AGPAT9 could significantly inhibit the V-ATPase activity and extracellular hydrogen ion concentration, and in turn the activation of secreted MMP-2/MMP-9, which ultimately suppressed tumor's invasion. AGPAT9 inhibited breast cancer proliferation through, at least in part, suppressing the V-ATPase activity and Wnt/B-catenin pathway. 
Collection (ATCC, Manassas, VA). Human breast cancer cell line Bcap-37 was purchased from the Committee on Type Culture Collection of Chinese Academy of Sciences (Shanghai, China).

\section{Vector constructs and lentivirus production}

The AGPAT9 lentivirus expression vector was constructed by amplifying the coding sequence of human AGPAT9 and cloning it into the LV5/GFP/Puro (Genepharma, Shanghai, China) or LV6/Puro vector (Genepharma, Shanghai, China). Oligonucleotides were synthesized to generate an annealing shRNA targeting the sequence of AGPAT9 from position 606-626 (5'-GGGAACTCTGATCCAGTATA T-3'), 709-729 (5'-GGAAAGTGGCCACAGATAATG-3'), 758-778 (5'-GGACCT GCCTAATTACCTTCA-3') or from 12041224 (5'-GGAGGAGAGAAGATAGGT ATT-3'). The fragments were cloned separately into pGLV3/H1/GFP/ Puro vector (Genepharma, Shanghai, China) using the restriction sites BamHI and EcoRI.

The LASS2 lentivirus expression and shRNAexpressing vector were detailed in our previous study [11]. The other plasmids or recombinant vectors used are shown in Supplementary Tables 1 and 2.

\section{Quantitative real-time PCR}

Real-time PCR analyses were performed with SYBR Premix Ex Taq (TaKaRa). The sequences of primers used were as follows: AGPAT9: 5'-CACCGTGACCGACCTATTC-3' and 5'-GCCCAGCGTCTGAGTTTT-3'; LASS2: 5'-GCCCAAGCAGGTGGAAGTAGAG-3' and 5'-CCAGGGTTTA-TCCACAATGACG-3'.

\section{Chromatin immunoprecipitation assay}

The assay was performed using the EZ-ChIP ${ }^{\mathrm{TM}}$ kit (\#17-371, Millipore, Billerica, MA) according to the manufacturer's instructions. The following antibodies were utilized to immunoprecipitate crosslinked proteinDNA complexes: rabbit anti-KLF4 (sc-20691, Santa Cruz) and normal rabbit IgG (12-370, Millipore). The immunoprecipitated DNA was purified for PCR analyses with primers within the promoter of LASS2.

\section{Activity of V-ATPase}

Assays were performed as described previously by us $[11,27]$.

\section{Measurement of extracellular $\mathrm{pH}$ and intracellular $\mathbf{p H}$}

Assays were performed as described previously by us $[11,27]$.

\section{Protein extraction and western blotting}

Total protein was extracted from the homogenate of cells using the T-PER Tissue Protein Extraction Reagent (Thermo Scientific, \#78510). The proteins were separated by SDS-PAGE and transferred to nitrocellulose membrane (Bio-Rad, Hercules, CA). The membrane was blocked with 5\% non-fat milk and incubated with rabbit anti-AGPAT9 polyclonal antibody (pAb) (Sigma Aldrich) (1:1000), rabbit anti-KLF4 pAb (Santa Cruz Biotechnology) (1:1000), rabbit anti-LASS2 pAb (Santa Cruz Biotechnology) (1:1000), rabbit anti- $\beta$-catenin monoclonal antibody (mAb) (Cell Signaling Technology) (1:1000), rabbit anti-Histone $\mathrm{H} 3 \mathrm{pAb}$ (Santa Cruz Biotechnology) (1:1000), rabbit anti-c-Myc mAb (Cell Signaling Technology) (1:1000), rabbit anti-Cyclin D1 mAb (Cell Signaling Technology) (1:1000), rabbit antiAxin-2 mAb (Cell Signaling Technology) (1:1000) or mouse anti-CD44 mAb (Cell Signaling Technology) $(1: 1000)$. The proteins were detected with enhanced chemiluminescence reagents (Pierce).

\section{Xenograft model and treatments}

Two different mouse models were used to observe in vivo effect of AGPAT9 on breast cancer cells. For the subcutaneous model, 17 $\beta$-estradiol pellets (NE-121, Innovative Research of America, Sarasota, FL) were subcutaneously implanted into the left shoulder area of mice 3 days before tumor cell injection. MCF7 cells $\left(1 \times 10^{7}\right)$ with stable knockdown of $A G P A T 9$ or the control vector were suspended in $200 \mu \mathrm{l}$ serum-free DMEM and subcutaneously injected into the right upper flank of each mouse (ten per group, female BALB/c-nu/nu, 8 weeks old) $[39,40]$. At day 11 after cell injection, mice were allocated to the Lenti-shRNA-vector group and LentishRNA-AGPAT9 group. The tumors were measured using digital calipers every 3 to 4 days after they reached a volume of $100 \mathrm{~mm}^{3}$, and tumor volumes were calculated as described: $\mathrm{V}\left(\mathrm{cm}^{3}\right)=\mathrm{Width}^{2}\left(\mathrm{~cm}^{2}\right) \times$ Length $(\mathrm{cm}) / 2$. At the termination of the experiment, the mice were sacrificed by cervical dislocation, and the tumors were weighed immediately after dissection.

For lung metastasis experiments, MDA-MB-231 (1.5 $\times 10^{6}$ ) stably expressing $A G P A T 9$ or the control vector were suspended in $200 \mu \mathrm{l}$ PBS and injected into the tail veins of each mouse (female BALB/c-nu/nu, 8 weeks old) [41]. Then, the animals were equally divided into two groups (ten per group): Lenti-vector group and Lenti- AGPAT9 group. At day 100 after cell injection, the mice were sacrificed by cervical dislocation, and their lungs were removed and subjected to hematoxylin and eosin (H\&E) staining. Mice were manipulated and housed according to the protocols approved by the Committee on the Ethics of Animal Experiments of Jiangsu Normal University. 


\section{Statistical analysis}

The results are presented as the means and s.e.m. The data were subjected to Student's $t$-test (two-tailed; $P<0.05$ was considered significant) unless otherwise specified ( $\chi^{2}$ test, Pearson's correlation, and linear regression).

\section{ACKNOWLEDGMENTS}

This work was supported by the Priority Academic Program Development of Jiangsu Higher Education Institutions, the Scientific Research Support Project for Teachers with Doctor's Degrees (Jiangsu Normal University, 13XLR045), the Clinical Technology Development of Jiangsu University (JLY20140130), the Natural Science Foundation for Colleges and Universities in Jiangsu Province (12KJB320001), the National Natural Science Foundation of China (81171012, 81271225, and 30950031).

\section{CONFLICTS OF INTEREST}

The authors have declared that no conflicts of interest exists.

\section{REFERENCES}

1. Siegel R, Ma J, Zou Z, Jemal A. Cancer statistics, 2014. CA Cancer J Clin. 2014; 64:9-29.

2. Cruciat CM, Ohkawara B, Acebron SP, Karaulanov E, Reinhard C, Ingelfinger D, Boutros M, Niehrs C. Requirement of prorenin receptor and vacuolar H+-ATPase-mediated acidification for Wnt signaling. Science. 2010; 327:459-463.

3. Rojas JD, Sennoune SR, Maiti D, Bakunts K, Reuveni M, Sanka SC, Martinez GM, Seftor EA, Meininger CJ, Wu G, Wesson DE, Hendrix MJ, Martínez-Zaguilán R. Vacuolartype $\mathrm{H}+$-ATPases at the plasma membrane regulate $\mathrm{pH}$ and cell migration in microvascular endothelial cells. Am J Physiol Heart Circ Physiol. 2006; 291:H1147-H1157.

4. Rofstad EK, Mathiesen B, Kindem K, Galappathi K. Acidic extracellular $\mathrm{pH}$ promotes experimental metastasis of human melanoma cells in athymic nude mice. Cancer Res. 2006; 66:6699-6707.

5. Fais S, De Milito A, You H, Qin W. Targeting vacuolar $\mathrm{H}+$-ATPases as a new strategy against cancer. Cancer Res. 2007; 67:10627-10630.

6. Chung C, Mader CC, Schmitz JC, Atladottir J, Fitchev P, Cornwell ML, Koleske AJ, Crawford SE, Gorelick F. The vacuolar-ATPase modulates matrix metalloproteinase isoforms in human pancreatic cancer. Lab Invest. 2011; 91:732-743.

7. Sennoune SR, Bakunts K, Martinez GM, Chua-Tuan JL, Kebir Y, Attaya MN, Martínez-Zaguilán R. Vacuolar $\mathrm{H}+$-ATPase in human breast cancer cells with distinct metastatic potential: distribution and functional activity. Am J Physiol Cell Physiol. 2004; 286:C1443-C1452.
8. Wiedmann RM, von Schwarzenberg K, Palamidessi A, Schreiner L, Kubisch R, Liebl J, Schempp C, Trauner D, Vereb G, Zahler S, Wagner E, Müller R, Scita G, et al. The V-ATPase-inhibitor archazolid abrogates tumor metastasis via inhibition of endocytic activation of the Rho-GTPase Rac1. Cancer Res. 2012; 72:5976-5987.

9. Lu X, Qin W, Li J, Tan N, Pan D, Zhang H, Xie L, Yao G, Shu H, Yao M, Wan D, Gu J, Yang S. The growth and metastasis of human hepatocellular carcinoma xenografts are inhibited by small interfering RNA targeting to the subunit ATP6L of proton pump. Cancer Res. 2005; 65:6843-6849.

10. Pan H, Qin WX, Huo KK, Wan DF, Yu Y, Xu ZG, Hu QD, Gu KT, Zhou XM, Jiang HQ, Zhang PP, Huang Y, Li YY, et al. Cloning, mapping, and characterization of a human homologue of the yeast longevity assurance gene LAG1. Genomics. 2001; 77:58-64.

11. Fan S, Niu Y, Tan N, Wu Z, Wang Y, You H, Ke R, Song J, Shen Q, Wang W, Yao G, Shu H, Lin H, et al. LASS2 enhances chemosensitivity of breast cancer by counteracting acidic tumor microenvironment through inhibiting activity of V-ATPase proton pump. Oncogene. 2013; 32:1682-1690.

12. Wang YY, Gao LY, Zhao YH, Li JY, Luo Q, Fan SH. Expression of CERS2 in invasive breast cancer tissues and its clinical significance. Zhonghua Bing Li Xue Za Zhi. 2013; 42:267-268.

13. Akaogi K, Nakajima Y, Ito I, Kawasaki S, Oie SH, Murayama A, Kimura K, Yanagisawa J. KLF4 suppresses estrogen-dependent breast cancer growth by inhibiting the transcriptional activity of ER $\alpha$. Oncogene. 2009; 28:2894-2902.

14. Yori JL, Seachrist DD, Johnson E, Lozada KL, AbdulKarim FW, Chodosh LA, Schiemann WP, Keri RA. Krüppel-like factor 4 inhibits tumorigenic progression and metastasis in a mouse model of breast cancer. Neoplasia. 2011; 13:601-610.

15. Yori JL, Johnson E, Zhou G, Jain MK, Keri RA. Kruppellike factor 4 inhibits epithelial-to-mesenchymal transition through regulation of E-cadherin gene expression. J Biol Chem. 2010; 285:16854-16863.

16. Shindou H, Shimizu T. Acyl-CoA: lysophospholipid acyltransferases. J Biol Chem. 2009; 284:1-5.

17. Ridgway ND. The role of phosphatidylcholine and choline metabolites to cell proliferation and survival. Crit Rev Biochem Mol Biol. 2013; 48:20-38.

18. Chen YQ, Kuo MS, Li S, Bui HH, Peake DA, Sanders PE, Thibodeaux SJ, Chu S, Qian YW, Zhao Y, Bredt DS, Moller DE, Konrad RJ, et al. AGPAT6 is a novel microsomal glycerol-3-phosphate acyltransferase. J Biol Chem. 2008; 283:10048-10057.

19. Shindou H, Hishikawa D, Harayama T, Yuki K, Shimizu T. Recent progress on acyl CoA: lysophospholipid acyltransferase research. J Lipid Res. 2009; :S46-51. 
20. Agarwal AK, Sukumaran S, Bartz R, Barnes RI, Garg A. Functional characterization of human 1-acylglycerol3-phosphate-O-acyltransferase isoform 9: cloning, tissue distribution, gene structure, and enzymatic activity. J Endocrinol. 2007; 193:445-457.

21. Harayama T, Shindou H, Ogasawara R, Suwabe A, Shimizu T. Identification of a novel noninflammatory biosynthetic pathway of platelet-activating factor. J Biol Chem. 2008; 283:11097-11106.

22. Cheng L, Han X, Shi Y. A regulatory role of LPCAT1 in the synthesis of inflammatory lipids, PAF and LPC, in the retina of diabetic mice. Am J Physiol Endocrinol Metab. 2009; 297:E1276-E1282.

23. Balaban S, Lee LS, Schreuder M, Hoy AJ. Obesity and Cancer Progression: Is There a Role of Fatty Acid Metabolism? Biomed Res Int. 2015; 2015:274585.

24. Agarwal AK. Lysophospholipid acyltransferases: 1acylglycerol-3-phosphate O-acyltransferases. From discovery to disease. Curr Opin Lipidol. 2012; 23:290-302.

25. Veiseh M, Kwon DH, Borowsky AD, Tolg C, Leong HS, Lewis JD, Turley EA, Bissell MJ. Cellular heterogeneity profiling by hyaluronan probes reveals an invasive but slow-growing breast tumor subset. Proc Natl Acad Sci USA. 2014; 111:E1731-E1739.

26. Fontanil T, Rúa S, Llamazares M, Moncada-Pazos A, Quirós PM, García-Suárez O, Vega JA, Sasaki T, Mohamedi Y, Esteban MM, Obaya AJ, Cal S. Interaction between the ADAMTS-12 metalloprotease and fibulin-2 induces tumor-suppressive effects in breast cancer cells. Oncotarget. 2014; 5:1253-1264.

27. Tang N, Jin J, Deng Y, Ke RH, Shen QJ, Fan SH, Qin WX. LASS2 interacts with V-ATPase and inhibits cell growth of hepatocellular carcinoma. Sheng Li Xue Bao. 2010; 62:196-202.

28. Wang $Y$, van der Zee M, Fodde R, Blok LJ. Wnt/ $\beta$-catenin and sex hormone signaling in endometrial homeostasis and cancer. Oncotarget. 2010; 1:674-684.

29. Valencia T, Kim JY, Abu-Baker S, Moscat-Pardos J, Ahn CS, Reina-Campos M, Duran A, Castilla EA, Metallo CM, Diaz-Meco MT, Moscat J. Metabolic reprogramming of stromal fibroblasts through p62-mTORC1 signaling promotes inflammation and tumorigenesis. Cancer Cell. 2014; 26:121-135.

30. Pellegrini P, Strambi A, Zipoli C, Hagg-Olofsson M, Buoncervello M, Linder S, De Milito A. Acidic extracellular $\mathrm{pH}$ neutralizes the autophagy-inhibiting activity of chloroquine: implications for cancer therapies. Autophagy. 2014; 10:562-571.

31. Graham RM, Thompson JW, Webster KA. Inhibition of the vacuolar ATPase induces Bnip3-dependent death of cancer cells and a reduction in tumor burden and metastasis. Oncotarget. 2014; 5:1162-1173.

32. Camargo Lde L, Babelova A, Mieth A, Weigert A, Mooz J, Rajalingam K, Heide H, Wittig I, Lopes LR, Brandes RP. Endo-PDI is required for TNF $\alpha$-induced angiogenesis. Free Radic Biol Med. 2013; 65:1398-1407.

33. Hermle T, Saltukoglu D, Grunewald J, Walz G, Simons M. Regulation of Frizzled-dependent planar polarity signaling by a V-ATPase subunit. Curr Biol. 2010; 20:1269-1276.

34. Bernhard SM, Seidel K, Schmitz J, Klare S, Kirsch S, Schrezenmeier E, Zaade D, Meyborg H, Goldin-Lang P, Stawowy P, Zollmann FS, Unger T, Funke-Kaiser H. The (pro)renin receptor ((P)RR) can act as a repressor of Wnt signalling. Biochem Pharmacol. 2012; 84:1643-1650.

35. Lou PJ, Lai PS, Shieh MJ, Macrobert AJ, Berg K, Bown SG. Reversal of doxorubicin resistance in breast cancer cells by photochemical internalization. Int J Cancer. 2006; 119:2692-2698.

36. Mahoney BP, Raghunand N, Baggett B, Gillies RJ. Tumor acidity, ion trapping and chemotherapeutics I. Acid $\mathrm{pH}$ affects the distribution of chemotherapeutic agents in vitro. Biochem Pharmacol. 2003; 66:1207-1218.

37. Gervasoni JE Jr, Fields SZ, Krishna S, Baker MA, Rosado M, Thuraisamy K, Hindenburg AA, Taub RN. Subcellular distribution of daunorubicin in P-glycoproteinpositive and -negative drug-resistant cell lines using laser-assisted confocal microscopy. Cancer Res. 1991; 51:4955-4963.

38. Coley HM, Amos WB, Twentyman PR, Workman P. Examination by laser scanning confocal fluorescence imaging microscopy of the subcellular localisation of anthracyclines in parent and multidrug resistant cell lines. Br J Cancer. 1993; 67:1316-1323.

39. Fan SH, Wang YY, Lu J, Zheng YL, Wu DM, Li MQ, Hu B, Zhang ZF, Cheng W, Shan Q. Luteoloside suppresses proliferation and metastasis of hepatocellular carcinoma cells by inhibition of NLRP3 inflammasome. PLoS One. 2014; 9:e89961.

40. Ben-Batalla I, Seoane S, Garcia-Caballero T, Gallego R, Macia M, Gonzalez LO, Vizoso F, Perez-Fernandez R. Deregulation of the Pit-1 transcription factor in human breast cancer cells promotes tumor growth and metastasis. J Clin Invest. 2010; 120:4289-4302.

41. Ai J, Tang Q, Wu Y, Xu Y, Feng T, Zhou R, Chen Y, Gao X, Zhu Q, Yue X, Pan Q, Xu S, Li J, et al. The role of polymeric immunoglobulin receptor in inflammationinduced tumor metastasis of human hepatocellular carcinoma. J Natl Cancer Inst. 2011; 103:1696-1712. 